\title{
Study on effect of layup angles on Vibration of Glass Fiber Reinforced Polymer (GFRP) Plate
}

\author{
Rahul Gangurde ${ }^{1}$, Dr. E. R. Deore ${ }^{2}$ \\ PG Student, Mechanical Department, SSVPSCOE, Dhule, Maharashtra, India ${ }^{1}$ \\ H.O.D, Mechanical Department, SSVPSCOE, Dhule, Maharashtra, India ${ }^{2}$
}

\begin{abstract}
The focus of this paper is to study the effect of lay-up angles on the vibrational frequencies of the Glass Fiber Reinforced Polymer (GFRP) plates. Light weight materials and design have always been an important topic in product design across several industries. Composite material gives chances to designers and engineers to increase material efficiency, therefore resulting in cost reduction and better utilization of resources. Composites materials applications are wide in aerospace industries, automobile sector, manufacturing industries etc. This study involves extensive experimental works to investigate the free vibration of woven E-fiber Glass/Epoxy composite plates in fixfree boundary conditions. The specimens of woven E-glass fiber and epoxy matrix composite plates are manufactured by the hand-lay-up technique which is most suitable and efficient manufacturing technique for composite manufacturing. Lay-up angles selected for the study are $(0,90),(60,30)$ and $(45,-45)$ and two different aspect ratios 1 and 1.5 are selected for the study. Manufacturing, experimental investigation is performed on the samples and FEA analysis is performed on the models of the plates.
\end{abstract}

Keywords: GFRP, Composite Material, Weight Reduction, Vibration Frequencies.

\section{INTRODUCTION}

Lightweight materials and design have always been an important topic in product design across several industries. The concept has been most important in aviation but also in industries where large rotating parts (e.g., rotor blades of wind turbines) are key elements of product design and in automotive, where driving dynamics are a major consideration. Global trends toward $\mathrm{CO} 2$ reduction and resource efficiency have significantly increased the importance of this topic over the last years.

Composite material has turned up as one of the major replacement for the conventional materials for weight reduction. Composite material has higher strength to weight ratio which results in to replacement of the conventional components with weight reduction and higher modal frequencies of the components.

A composite is a structural material that consists of two or more combined constituents that are combined at a macroscopic level and are not soluble in each other. One constituent is called the reinforcing phase and the one in which it is embedded is called the matrix. The reinforcing phase material may be in the form of fibers, particles, or flakes. The matrix phase materials are generally continuous. Examples of composite systems include concrete reinforced with steel and epoxy reinforced with graphite, fibers, etc.

Hand Lay-up method will be used for the manufacturing of the composite plates. This technique is the simplest method of composite processing. The infrastructural requirement for this method is also minimal. The processing steps are quite simple. First of all, a release gel is sprayed on the mould surface to avoid the sticking of polymer to the surface. Thin plastic sheets are used at the top and bottom of the mould plate to get good surface finish of the product. Reinforcement in the form of woven mats or chopped strand mats are cut as per the mould size and placed at the surface of mould after Perspex sheet.

Then thermosetting polymer in liquid form is mixed thoroughly in suitable proportion with a prescribed hardener (curing agent) and poured onto the surface of mat already placed in the mould. Process is repeated for all the layers and then curing time will be given to the moulded material while pressure is applied on the mould.

Vibration is a mechanical phenomenon whereby oscillations occur about an equilibrium point. Vibration can be desirable in few cases, however, vibration is undesirable in the most, wasting energy and creating unwanted sound. There are different types of vibration which includes Free, Forced on the basis of nature of force and damped, un-damped on the basis of use of damper. Careful designs usually minimize unwanted vibrations. Most of the times simple systems can be represented using spring, mass damper system as shown in the figure below.

Vibration equation is formulated and can be solved to find out natural frequencies of the system. Ordinary differential equation that represents the vibration is given by

$$
m \cdot \frac{d^{2} x}{d t^{2}}+c \cdot \frac{d x}{d t}+k \cdot x=f(t)
$$


Vol. 4, Issue 1, January 2017

\section{LITERATURE REVIEW}

The purpose of the literature review is to understand the work done and understand composite material layers effect on the vibration frequencies of plate. Swapnil Sanjay Chavan presented his study on "Study on Vibration Analysis of Composite Plate." This paper represents the review on vibration analysis of composite plates. The author says that vibration and composite material are two main growing research topics now-a-days. Almost all the structural components subjected to dynamic loading in their working life and vibration affects working life of the structure so it is very important in designing a structure to know in advance its response and to take necessary steps to control the structural vibration and its amplitude. Composite material gives opportunity to designer and engineer to increase material efficiency, resulting in cost reduction and better utilization of resources. Composites materials applications are wide in aerospace industries, automobile sector, manufacturing industries etc. This study involves extensive experimental work to investigate the free vibration of woven fiber glass/epoxy composites plates in free-free boundary condition and the author was interested to do research in fixed-free boundary condition of composite plates.

Vibration of plates depends greatly on its thickness, aspect ratio, boundary condition and fiber orientation. In this paper the author studies different mode frequency for free vibration according to change in aspect ratio, thickness and fiber orientation. The specimens of woven glass fiber and epoxy matrix composite plates were manufactured by the hand-layup techniques. Elastic parameters are determined experimentally by tensile testing of specimens. An experimental investigation is carried out using modal analysis technique to obtain the natural frequencies by using FFT analyzer. Also another analysis runs on ANSYS to validate the results. This study provides valuable information for researchers, engineers and composite material industries in design applications.[1]

Itishree Mishra \&Shishir Kumar Sahu submitted their work on "An Experimental Approach to Free Vibration Response of Woven Fiber Composite Plates under FreeFree Boundary Condition." This present study involves extensive experimental works to investigate the free vibration of woven fiber Glass/Epoxy composite plates in free-free boundary conditions. The specimens of woven glass fiber and epoxy matrix composite plates are manufactured by the hand-layup technique. Elastic parameters of the plate are also determined experimentally by tensile testing of specimens using Instron 1195. An experimental investigation is carried out using modal analysis technique with Fast Fourier Transform Analyzer, PULSE lab shop, impact hammer and contact accelerometer to obtain the Frequency Response Functions. Also, this experiment was used to validate the results obtained from the FEM numerical analysis based on a first order shear deformation theory. The effects of different geometrical parameters including number of layers, aspect ratio, and fiber orientation of woven fiber composite plates are studied in free-free boundary conditions in details. This study provides valuable information for researchers and engineers in design applications.[2]

S. S. Chavan and M. M. Joshi presented their research on "Study on Vibration Analysis of Composite Plate". In this research the researcher has said that vibration and composite material are two main growing research topics these days. Almost all the structural components subjected to dynamic loading in their working life and vibration affects the working life of the structure so it is very important in designing a structure to know in advance its response and to take necessary steps to control the structural vibration and its amplitude. Composite material gives chances to designers and engineers to increase material efficiency, therefore resulting in cost reduction and better utilization of resources. Composites materials applications are wide in aerospace industries, automobile sector, manufacturing industries etc. This study involves extensive experimental works to investigate the free vibration of woven E-fiber Glass/Epoxy composite plates in fix-free boundary conditions. The specimens of woven E-glass fiber and epoxy matrix composite plates are manufactured by the hand-lay-up technique which is most suitable and efficient manufacturing technique for composite manufacturing. Elastic properties of the plate are also determined experimentally by tensile testing of specimens using computerized universal testing machine TUE-C-400. ASTM standard was used to test the material. An experimental investigation was carried out using modal analysis technique with VA4Pro FFT Analyzer, impact hammer and contact accelerometer obtains the Frequency Response Functions. Also, this experiment was used to validate the results obtained from the ANSYS 15.0 and theoretical calculations based on governing equation of vibration. The effects of different geometrical parameters including number of layers, aspect ratio of woven E-glass fiber composite plates are studied in fix-free boundary conditions in details. This study provided valuable information for researchers and engineers in design applications.[3]

Dr. K. Srividya, M. Nagaswapnasri, E. Kavitha and P. Anusha submitted their work on "Free Vibration Of Thick Rectangular Debonded Metallic Plates: Analytical And Experimental Approach" In this investigation, free vibration analysis of thick isotropic materials of debonded metallic plates under various boundary conditions was found using finite element method. In addition experiments were conducted on thick debonded metallic plates to validate FEM with experimental modal analysis also. The finite element models (FEM) which use the elasticity theory for the determination of stiffness matrices were modeled in ANSYS software to evaluate the first natural frequencies of the laminate. The variation of natural frequencies with respect to various debondedisotropic materials like stainless steel and aluminium was presented.[4] 
Vol. 4, Issue 1, January 2017

G. V. Mahajan and Prof. V. S. Aher presented their research on "Composite Material: A Review over Current Development and Automotive Application." In this paper, the authors have said that the importance of materials in modern world can be realized from the fact that much of the research is being done to apply new materials to different components.

However it is natural for a design engineer to rely on trusted and tested materials, but now the world is changing. Today composite materials have changed all the material engineering. The evolution of composite materials has given an opportunity to various designers to use new and better materials resulting in cost reduction, increase in efficiency and better utilization of available resources. Composite materials are finding their applications in aerospace industry, automobile sector, manufacturing industries etc. This paper presents design method and vibrational analysis of composite propeller shafts. In this paper, the aim is to replace a metallic drive shaft by a two-piece composite drive shaft. Designing of a composite drive shaft is divided in two main sections: design of the composite shaft and design of couplings. In composite shaft design some parameters such as critical speed, static torque and adhesive joints are studied; the behavior of materials is considered nonlinear isotropic for adhesive, linear isotropic for metal and orthotropic for composite shaft. Along with the design all the analyses are performed using finite element software (ANSYS). The results show significant points about optimum design of composite drive shafts.[5]

R. Rikards, A. Chate and O. Ozolinsh presented their work on "Analysis for Buckling and Vibrations of Composite Stiffened Shells and Plates." This paper deals with development of triangular finite element for buckling and vibration analysis of laminated composite stiffened shells. For the laminated shell, an equivalent layer shell theory is employed. The first-order shear deformation theory including extension of the normal line is used. In order to take into account a non-homogeneous distribution of the transverse shear stresses a correction of transverse shear stiffness is employed.

Based on the equivalent layer theory with six degrees of freedom (three displacements and three rotations), a finite element that ensures $\mathrm{C}^{0}$ continuity of the displacement and rotation fields across inter-element boundaries has been developed. Numerical examples are presented to show the accuracy and convergence characteristics of the element. Results of vibration and buckling analysis of stiffened plates and shells are discussed.[6]

C. Srinivasan, S. Vijayakumar, A. Kalaiyarasan, K. Pasupathi and S. Sasidharan presented their work on "Experimental Investigation on Vibration Characteristics of Jute Fiber Reinforced Composite Material" This work presents the vibrational characteristics of composite material that is formed by a jute fiber reinforced epoxy matrix composite. An experimental modal analysis was conducted on the composite material with cantilever beam structure to get the natural frequency, damping and mode shape. The experimental work is disbursed completely different for various layers of configuration by exciting the composite beam with different excitation frequencies by software model read package. The obtained mode shape reveals the deformation pattern of the structure like its natural frequency. Additionally the finite element modelling and analysis was disbursed by using ANSYS workbench for finding the natural frequencies and mode shapes of the finite element model of jute fiber reinforced epoxy matrix composite. Finally the finite part model of jute fiber reinforced epoxy matrix composite is valid with the obtained experimental results.[7]

Mutra Raja Sekhara Reddy, BathiniSidda Reddy, VanguruNageswara Reddy and SurisettySreenivasulu submitted their research on "Prediction of Natural Frequency of Laminated Composite Plates Using Artificial Neural Networks." The paper is focused on the application of artificial neural networks (ANN) in predicting the natural frequency of laminated composite plates under clamped boundary condition. For training and testing of the ANN model, a number of finite element analyses have been carried out using D-optimal design in the design of experiments (DOE) by varying the fibre orientations, $-45^{\circ}$, $0^{\circ}, 45^{\circ}$ and $90^{\circ}$. The composite plate is modeled using linear layered structural shell element. The natural frequencies were found by analyses which were done by finite element (FE) analysis software. The ANN model has been developed using multilayer perceptron (MLP) back propagation algorithm. The adequacy of the developed model is verified by coefficient of determination $(\mathrm{R})$.

It was found that the R2 ( $\mathrm{R}$ : coefficient of determination) values are 1 and 0.998 for train and test data respectively. The results showed that, the training algorithm of back propagation was sufficient enough in predicting the natural frequency of laminated composite plates. To judge the ability and efficiency of the developed ANN model, absolute relative error has been used. The results predicted by ANN are in very good agreement with the finite element (FE) results. Consequently, the D-optimal design and ANN are shown to be effective in predicting the natural frequency of laminated composite plates.[8]

A. Pagani, E. Carrera, J. R. Banerjee, P. H. Cabral, G. Caprio and A. Prado presented their paper on "Free Vibration Analysis of Composite Plates by Higher-Order 1D Dynamic Stiffness Elements And Experiments." In this paper a novel approach for free vibration analysis of composite plate-like structures was introduced. Refined beam theories were formulated by making use of the Carrera Unified Formulation (CUF). By exploiting the hierarchical characteristics of CUF, the differential equations of motions and the natural boundary conditions are written in a compact and concise form in terms of fundamental nuclei, whose formal mathematical expressions do not depend on the order of the theory N. After the closed form solution of the Nth order beam 
Vol. 4, Issue 1, January 2017

model is sought, a general procedure to derive the exact Dynamic Stiffness (DS) matrix is devised by relating the amplitudes of the harmonically varying loads to those of the responses. The global DS matrices of composite laminated plates are then used with reference to the algorithm of Wittrick and Williams to carry out free vibration analyses. The accuracy of the proposed methodology is verified through published literature, finite element solutions from the commercial code MSC/ NASTRAN and experimental tests.[9]

Pushpendra K. Kushwaha and JyotiVimal submitted their work on "Study of Vibration Analysis of Laminated Composite Plates Using FEM." The vibrational analysis of laminated composite plates is analysed using finite element method in this paper. Numerical results have been computed for the effect of number of layers, thickness ratio of plate, different boundary conditions, different aspect ratio, and different angle of fibre orientation of laminated composite plate. The analysis for rectangular plate is carried out for thickness $(\mathrm{h} / \mathrm{b}=0.001,0.01,0.05$, 0.1 , and 0.2$)$ and different aspect ratios $(\mathrm{a} / \mathrm{b}=1,1.5,2$, and 2.5). The problem of free vibration analysis of composite square plates having $(3,5,7$, and 9) lamina layers (angle ply and cross ply) is also considered.

The non-dimensional fundamental frequency of vibration is found to increase with increase of angle of fibre orientation and number of layers but non-dimensional fundamental frequency decrease with increase in size ratio and thickness to width ratio. The natural frequencies and mode shapes are compared for different boundary condition. Comparisons are made with the result for thin and thick composite laminated plate.[10]

\section{FINITE ELEMENT ANALYSIS}

In this section, we have analysed the GFRP plates using ANSYS software. The meshing of the GFPR plate is as shown in the figure below.

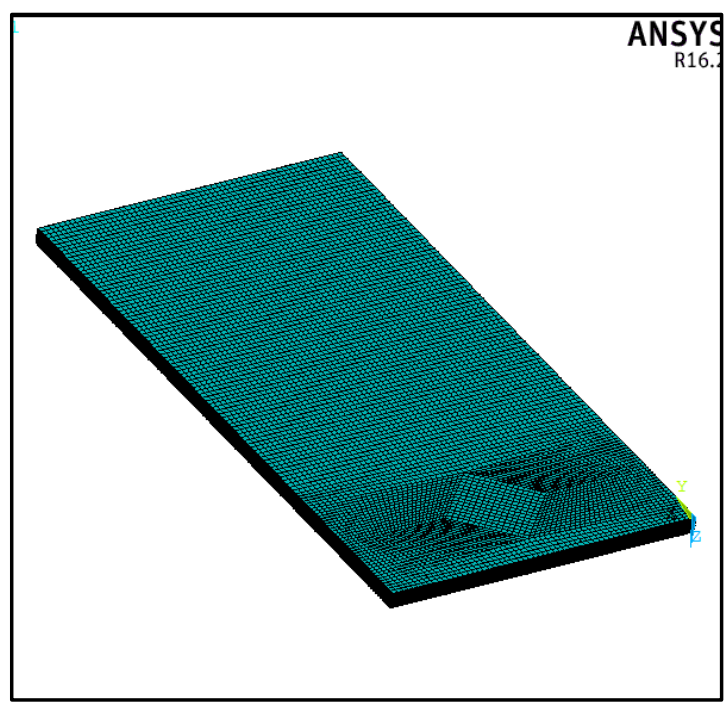

Fig. 1: Meshing of 0, 90 plate

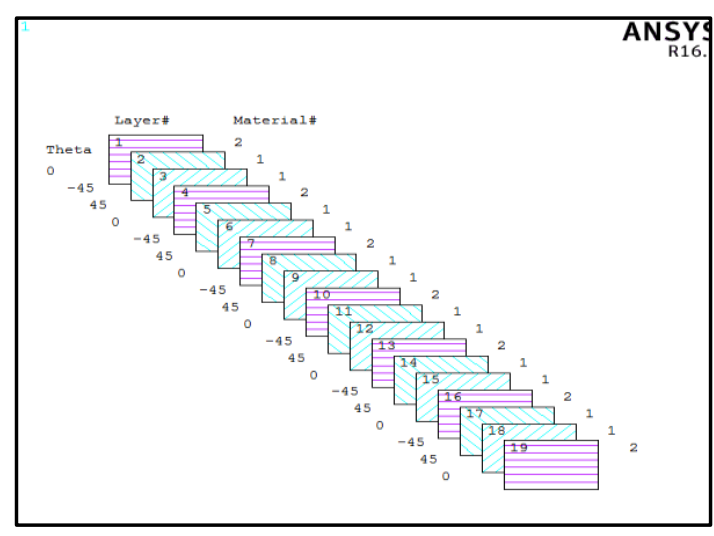

Fig. 2: Section plot @ 45-45

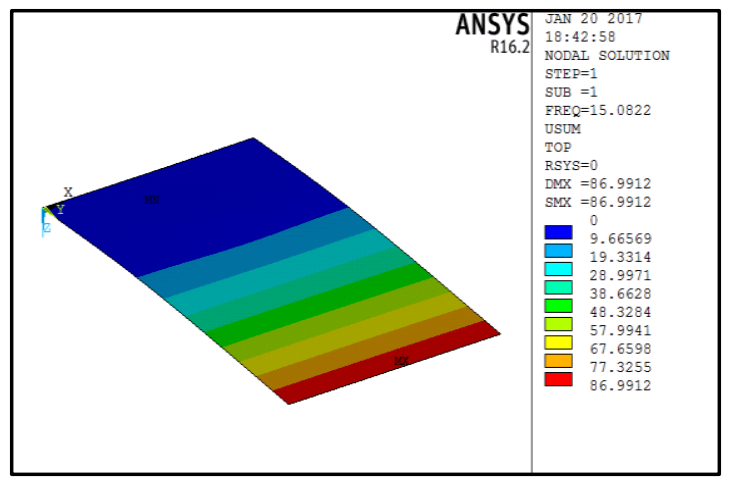

Fig. 3: Mode shape for plate 45, -451.5 length to width ratio

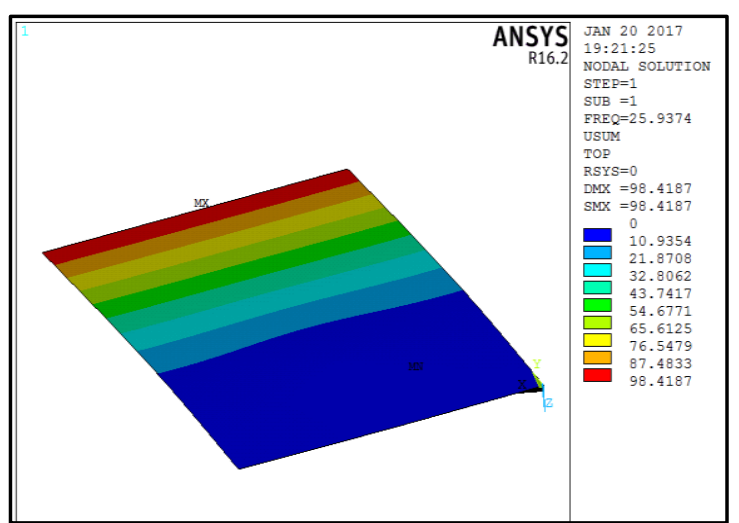

Fig. 4: Mode shape for plate 45, $-451 \mathrm{~mm}$ length to width ratio

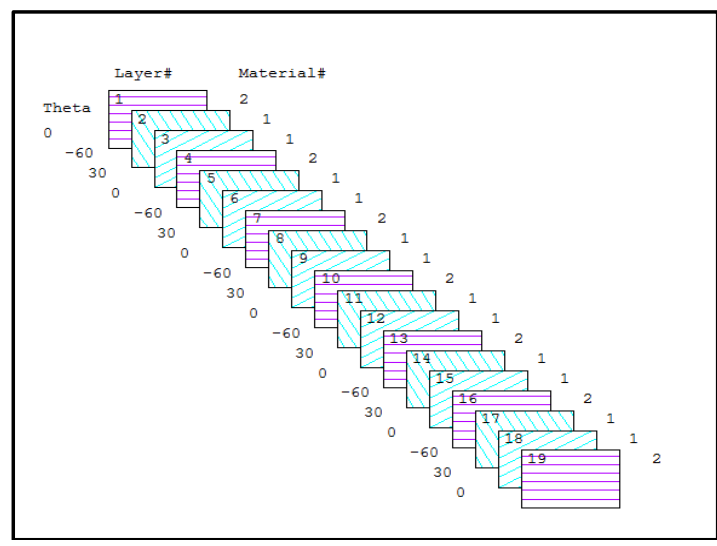

Fig. 5: Section with 30,-60 orientations 


\section{International Advanced Research Journal in Science, Engineering and Technology}

ISO 3297:2007 Certified

Vol. 4, Issue 1, January 2017

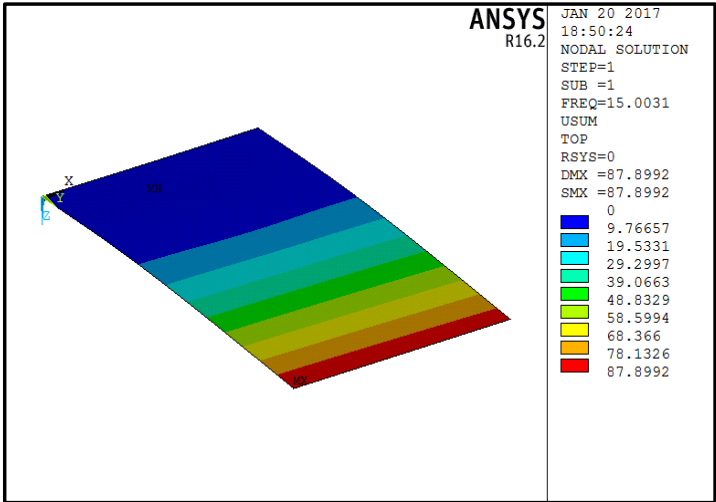

Fig. 6: Mode shape 1 _ $30-60$ plate 1.5 Length to width ratio plate

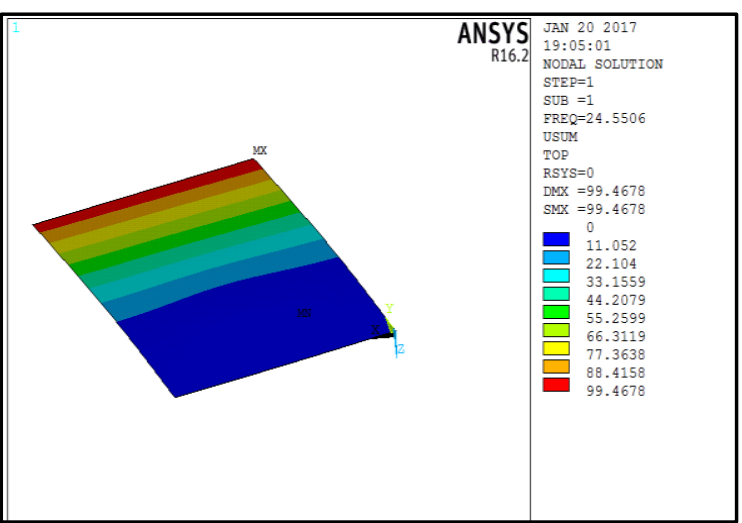

Fig. 7: Mode shape 1 _ 30-60 plate 1 Length to width ration plate

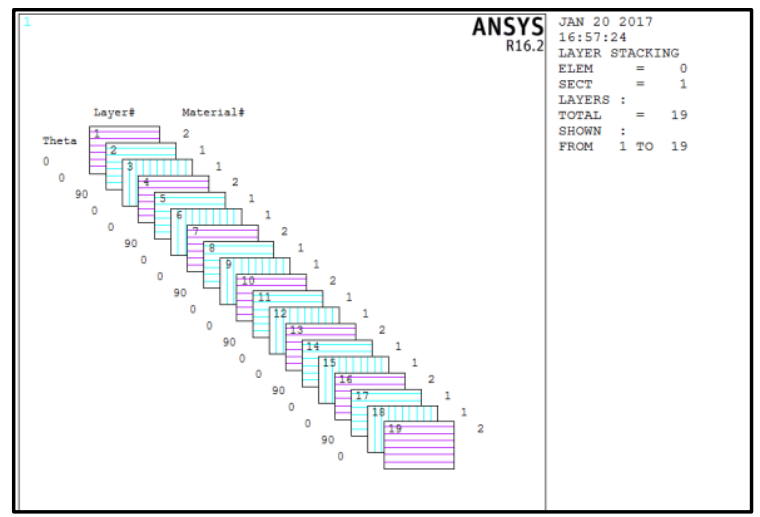

Fig. 8: Section plot for 0, 90 GFRP Plate

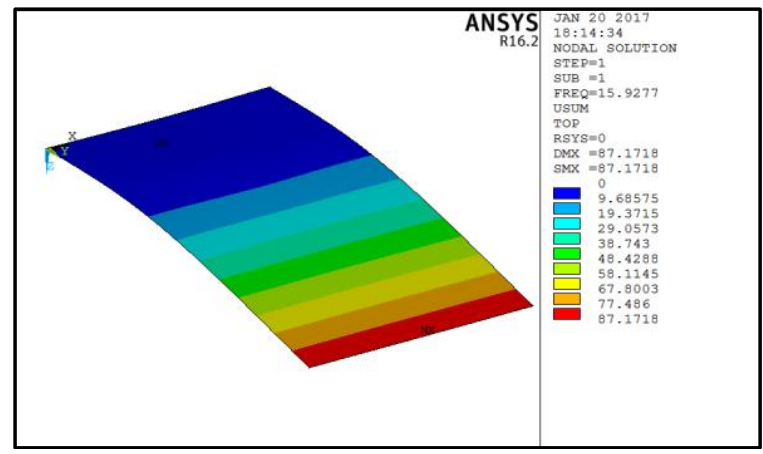

Fig. 9: Mode shape 1 for 0-90 plate 1.5 Length to width ratio plate

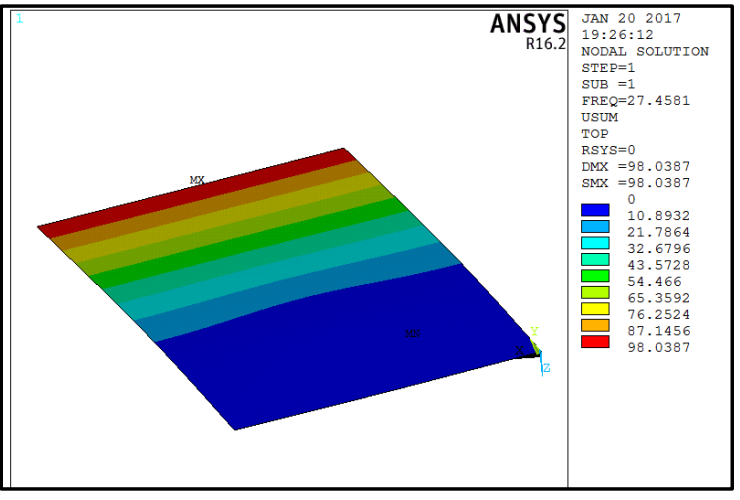

Fig. 10: Mode shape 1 _ $0-90$ plate 1 Length to width ratio plate

Table: Results obtained from FEA

\begin{tabular}{|c|c|c|c|}
\hline Plate No & Ratio & angle & Frequency FEA \\
\hline 1 & 1.5 & $45,-45$ & 15.1 \\
\hline 2 & 1.5 & $30,-60$ & 15 \\
\hline 3 & 1.5 & 0,90 & 15.93 \\
\hline 1A & 1 & $45,-45$ & 25.94 \\
\hline $2 \mathrm{~A}$ & 1 & $30,-60$ & 24.56 \\
\hline $3 \mathrm{~A}$ & 1 & 0,90 & 27.46 \\
\hline
\end{tabular}

\section{EXPERIMENTAL INVESTIGATION}

In experimental set up, the plate is mounted on a table, and one end of the plate is fixed to the table with the help of a C clamp. On the other end, the sensor of the FFT Analyser is attached. Then the connections of the FFT analyser are made and one test is done on the FFT to calibrate the connections and the machine. The setup is as shown in the image below.

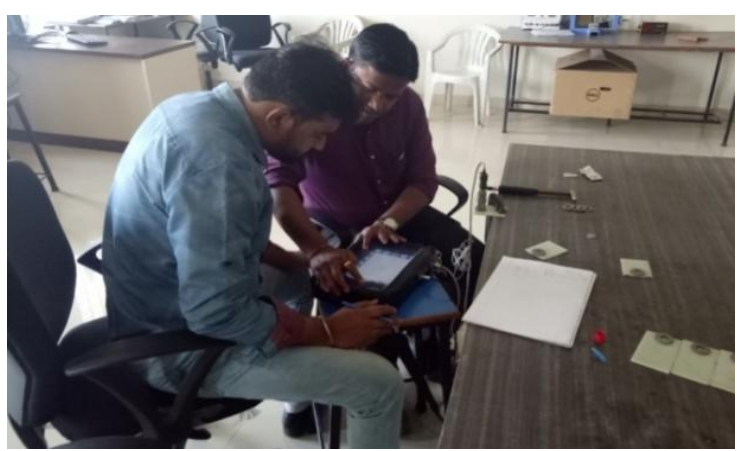

Fig. 11: Setup while performing experimentation

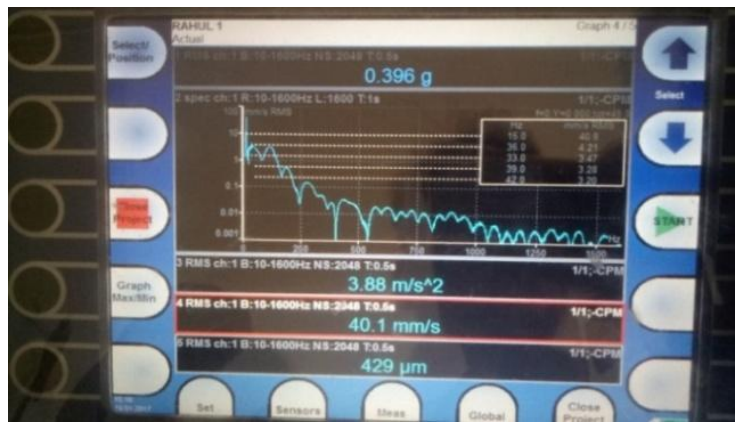

Fig. 12: Experimental result of 45, - 45 angle plate 
Table: Results obtained from experimental investigation

\begin{tabular}{|c|c|c|c|}
\hline PlateNo & Ratio & angle & FFT Testing \\
\hline 1 & 1.5 & $45,-45$ & 15 \\
\hline 2 & 1.5 & $30,-60$ & 14.5 \\
\hline 3 & 1.5 & 0,90 & 15.5 \\
\hline 1A & 1 & $45,-45$ & 26.5 \\
\hline 2A & 1 & $30,-60$ & 25 \\
\hline $3 \mathrm{~A}$ & 1 & 0,90 & 28 \\
\hline
\end{tabular}

\section{RESULTS AND DISCUSSION}

The results obtained from FEA and experimental investigation is mentioned in the table below.

From the above table, it is evident that the results obtained from the FEA and experimental investigation is in good coherence and thus the results are validated. From the results, we can say that the highest frequency is obtained for the ply angle 0, 90. Therefore this is the best layup angle for the GFRP Plate.

Table: Results obtained from FEA and Testing

\begin{tabular}{|c|c|c|c|c|}
\hline $\begin{array}{c}\text { Plate } \\
\text { No }\end{array}$ & $\begin{array}{c}\text { Aspect } \\
\text { Ratio }\end{array}$ & $\begin{array}{c}\text { Layup } \\
\text { angle }\end{array}$ & $\begin{array}{c}\text { Frequency } \\
\text { Testing }\end{array}$ & $\begin{array}{c}\text { Frequency } \\
\text { FEA }\end{array}$ \\
\hline 1 & 1.5 & $45,-45$ & 15 & 15.1 \\
\hline 2 & 1.5 & $30,-60$ & 14.5 & 15 \\
\hline 3 & 1.5 & 0,90 & 15.5 & 15.93 \\
\hline 1A & 1 & $45,-45$ & 26.5 & 25.94 \\
\hline 2A & 1 & $30,-60$ & 25 & 24.56 \\
\hline 3A & 1 & 0,90 & 28 & 27.46 \\
\hline
\end{tabular}

\section{CONCLUSION}

If we observe the results obtained above we can clearly see that the study of vibration analysis on the composite material is always been constrained to number of composite plies of different composite materials and aspect ratios of the plates used in composite. Though fibre orientation of the composite materials like GFRP and CFRP are very important parameters when effect on the vibrational frequencies is to be evaluated.

- We performed FFT analysis while experimental testing and found out vibrational frequencies for the free vibration of the plates at fix-free boundary conditions.

- By comparing vibrational frequencies of the composite plates with different lay -up angles $(0,90),(60,-30)$ and $(45,-45)$ using fix -free boundary condition for the plate, we see that the highest frequency is obtained for 0,90 .

- By studying the effect of angled ply on the vibration of plates with different aspect ratio we can say that the aspect ratio 1 is better that 1.5 .

\section{REFERENCES}

[1] Swapnil Sanjay Chavan, "Study on Vibration Analysis of Composite Plate." International Conference on Multidisciplinary Research \& Practice, VolumeI, 407-410, (2014)

[2] Itishree Mishra \& Shishir Kumar Sahu submitted their work on "An Experimental Approach to Free Vibration Response of Woven Fiber Composite Plates under Free-Free Boundary Condition." International Journal of Advanced Technology in Civil Engineering, 67-72, (2012)

[3] S. S. Chavan and M. M. Joshi "Study on Vibration Analysis of Composite Plate", International Journal Of Advances In Production And Mechanical Engineering, 69-76, (2015)

[4] Dr. K. Srividya, M. Nagaswapnasri, E. Kavitha and P. Anusha, "Free Vibration Of Thick Rectangular Debonded Metallic Plates: Analytical And Experimental Approach", Journal of Advance Research in Science and Engineering, 246-257, (2016)

[5] G. V. Mahajan and Prof. V. S. Aher "Composite Material: A Review over Current Development and Automotive Application." International Journal of Scientific and Research Publications, 22503153, (2012)

[6] R. Rikards, A. Chate and O. Ozolinsh, "Analysis for Buckling and Vibrations of Composite Stiffened Shells and Plates", ELSEVIER, Composite Structure 51 (2001), 361-370.

[7] C. Srinivasan, S. Vijayakumar, A. Kalaiyarasan, K. Pasupathi and S. Sasidharan, "Experimental Investigation on Vibration Characteristics of Jute Fiber Reinforced Composite Material", International Journal for Scientific Research \& Development, Vol4, 150-153, (2016)

[8] Mutra Raja Sekhara Reddy, BathiniSidda Reddy, Vanguru Nageswara Reddy and Surisetty Sreenivasulu, "Prediction of Natural Frequency of Laminated Composite Plates Using Artificial Neural Networks"ScientificResearch, Engineering,329-337,(2012)

[9] Pagani, E. Carrera, J. R. Banerjee, P. H. Cabral, G. Caprio and A. Prado, "Free Vibration Analysis of Composite Plates by HigherOrder 1D Dynamic Stiffness Elements And Experiments", ELSEVIER,composite Structure 118 (2014),654-663.

[10] Pushpendra K. Kushwaha and Jyoti Vimal, "Study of Vibration Analysis of Laminated Composite Plates Using FEM "International Journal of Advance Mechanical Engineering, Volume4, (2014), pp.- 675 . 